\title{
Exchange Protein Directly Activated by Cyclic AMP Isoform 2 Is Not a Direct Target of Sulfonylurea Drugs
}

\author{
Tamara Tsalkova, ${ }^{1}$ Alexey V. Gribenko, ${ }^{2}$ and Xiaodong Cheng ${ }^{1}$ \\ Departments of ${ }^{1}$ Pharmacology and Toxicology and ${ }^{2}$ Biochemistry \\ and Molecular Biology, The University of Texas Medical Branch, \\ Galveston, Texas.
}

\section{ABSTRACT}

It has been reported by Zhang et al. that antidiabetic sulfonylurea drugs promote insulin secretion by directly binding to exchange protein directly activated by cyclic AMP isoform 2 (Epac2) and activating its down-stream effector Rap1. However, a critical link for an unambiguous validation of a direct interaction between Epac2 and sulfonylurea using purified individual components is missing. Our in vitro analyses using purified full-length Epac2 and Rap1 suggest that sulfonylureas are not able to directly bind to Epac2, nor are they capable of triggering Epac2dependent Rap1 activation.

\section{INTRODUCTION}

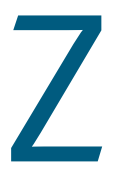

hang et al. reported that exchange protein directly activated by cAMP (Epac) isoform 2 is a direct target of sulfonylurea drugs. ${ }^{1}$ Epac is a cAMP-regulated guanine nucleotide exchange factors (GEF) with substrate specificity for small GTPases Rap1 and Rap2.. ${ }^{2,3}$ In response to cAMP, the two known intracellular cAMP receptors, Epac and protein kinase A/c AMPdependent protein kinase (PKA) may act independently, converge synergistically, or oppose each other in regulating various cellular functions depending upon the specific cellular environments. ${ }^{4}$ Two isoforms of Epac, Epac1 and Epac2, with distinct tissue expressions, have been identified in mammals. ${ }^{5}$ Epac2 has been implicated in regulating cAMP-mediated exocytosis in a variety of secretory cells. ${ }^{6}$

In pancreatic endocrine $\beta$ cells, Epac 2 is the major Epac isoform and mediates the glucose-induced insulin secretion potentiated by glucagon-like peptide 1 and gastric inhibitory polypeptide, which bind to receptor on the surface of $\beta$ cells and promote intracellular cAMP production. ${ }^{7}$ The effect of Epac 2 on insulin secretion in $\beta$ cells is mainly mediated by its influences on $\mathrm{Ca}^{2+}$ signaling. ${ }^{8}$ Epacselective agonist increases intracellular $\mathrm{Ca}^{2+}$ and induces insulin secretion in human $\beta$ cells. ${ }^{9}$ These observations can be partially ex- plained by the ability of Epac to directly form a protein complex with the ATP-sensitive potassium ion channel $\left(\mathrm{K}_{\mathrm{ATP}}\right)$ through interaction with the sulfonylurea receptor 1 , a regulatory subunit of $\mathrm{K}_{\mathrm{ATP}}{ }^{6}$ Indeed, Epac-selective agonist blocks the conductivity of the $\mathrm{K}_{\mathrm{ATP}}$ channel in pancreatic $\beta$ cells. ${ }^{10}$

It is widely accepted that sulfonylureas, a class of antidiabetic drugs commonly used in the management of type 2 diabetes mellitus, function through binding to sulfonylurea receptor 1 and blocking channel conductivity, which triggers membrane depolarization, $\mathrm{Ca}^{2+}$ influx, and insulin secretion from pancreatic $\beta$ cells. A recent report by Zhang et al. reports that Epac2 is a direct target of sulfonylureas. ${ }^{1}$ Zhang and colleagues based their conclusion on a series of experiments both in mice lacking Epac2 and in various cell models. They showed that sulfonylurea-stimulated insulin secretion was reduced in Epac2 knockout mice and sulfonylureas were capable of activating an Epac2-based fluorescence resonance energy transfer sensor in cells. Although their findings demonstrate that Epac2 plays an important role in mediating the pharmacological effects of sulfonylureas, their radioligand binding assay, a key experiment to support their conclusion that Epac2 is a direct target of sulfonylureas, was not performed on the candidate intracellular drug target in vitro, but rather in a whole-cell context. We, therefore, conduct a series of in vitro experiments using purified recombinant full-length Epac2 and Rap 1 to test the ability of sulfonylureas to directly interact with and to activate Epac2.

\section{MATERIALS AND METHODS \\ Materials}

All chemicals used in this study were of analytical grade. Tolbutamide [1-butyl-3-(4-methylphenylsulfonyl)urea] (TLB) was a product of Fluka Analytical and purchased from Sigma-Aldrich (St. Louis, MO). Glibenclamide (GLB) was a product of ALEXIS Biochemicals and purchased from Axxora (San Diego, CA). [H $\left.{ }^{3}\right]$ GLB was purchased from PerkinElmer (Waltham, MA).

In vitro GEF activity of Epac2 was measured using a well-established fluorescence-based assay. ${ }^{11}$ Briefly, $0.2 \mu \mathrm{M}$ of Rap1(1-167) loaded with the fluorescent GDP analog, 3'-0-( $N$-methylanthraniloyl) guanosine diphosphate (Mant-GDP), was incubated with $0.1 \mu \mathrm{M}$ of Epac2 in buffer containing $50 \mathrm{mM}$ Tris- $\mathrm{HCl}, \mathrm{pH} 7.5,5 \mathrm{mM} \mathrm{MgCl}_{2}$,

ABBREVIATIONS: Epac2, exchange protein directly activated by cyclic AMP isoform 2; GEF, guanine nucleotide exchange factors; GLB, Glibenclamide; ITC, isothermal titration calorimetry; Mant-GDP, 3'-0-(N-methylanthraniloyl) guanosine diphosphate; 8-NBD-cAMP, 8-[[2-[(7-nitro-4-benzofurazanyl)amino]ethyl] thio]adenosine3',5'-cyclic monophosphate; TLB, tolbutamide [1-butyl-3-(4-methylphenylsulfonyl)urea]. 
and $1 \mathrm{mM}$ DTT in the presence of a 100-fold molar excess of unlabeled GDP $(20 \mu \mathrm{M})$ and ligand of interest. Exchange of Mant-GDP by GDP was measured as a decrease in fluorescence intensity over time using excitation and emission wavelengths of 366 and $450 \mathrm{~nm}$, respectively. Typically, decay in the fluorescence intensity was recorded over a time course of $6,000 \mathrm{~s}$ with data points taken every $60 \mathrm{~s}$. The reaction rate constant (observed $k_{G E F}$ ) was obtained by fitting the experimental data to a single exponential equation. The dependence of observed $k_{G E F}$ on cAMP concentration was used to calculate the activation constant, $A C_{50}$, and turnover rate $k_{\max }$, as previously described. ${ }^{12}$

Epac2-ligand interaction was monitored by a competition assay that measures the displacement of a fluorescent cAMP analog, 8-[[2[(7-nitro-4-benzofurazanyl)amino]ethyl] thio]adenosine- $3^{\prime}, 5^{\prime}$-cyclic monophosphate (8-NBD-cAMP), whose fluorescence intensity increases dramatically upon binding to Epac2. ${ }^{13}$ Briefly, mixture of $0.05 \mu \mathrm{M}$ Еpac2/0.06 $\mu \mathrm{M}$ 8-NBD-cAMP in buffer $50 \mathrm{mM}$ Tris-HCl, $\mathrm{pH}$ 7.5, $150 \mathrm{mM} \mathrm{NaCl}, 1 \mathrm{mM}$ EDTA, and $1 \mathrm{mM}$ DTT was aliquoted to the 96-well plate (100 $\mu \mathrm{L}$ per well) and fluorescence intensity at $540 \mathrm{~nm}$ was recorded with the excitation wavelength set at $470 \mathrm{~nm}$. Then, different amount of the compound of interest was added to the wells (typically $1 \mu \mathrm{L}$ per well) and mixed carefully, and fluorescence intensity was recorded again.

Isothermal titration calorimetry (ITC) experiments were carried on a VP-ITC calorimeter (MicroCal; LLC, Northampton, MA) at $25^{\circ} \mathrm{C}$ and analyzed using Origin 7.0 software. Wild-type Epac2 at concentration $8-10 \mu \mathrm{M}$ was dialyzed extensively against buffer containing $20 \mathrm{mM}$ Tris, pH 7.4, $150 \mathrm{mM} \mathrm{NaCl}$, and $1 \mathrm{mM}$ EDTA. About $100 \mathrm{mM}$ cAMP stock solution was prepared in water, titrated to $\mathrm{pH} 7.4$ by addition of $6 \mathrm{M} \mathrm{NaOH}$ solution, and diluted to $1 \mathrm{mM}$ into dialysis buffer with 1\% dimethyl sulfoxide (DMSO). About $100 \mathrm{mM} \mathrm{GLB}$ stock solution was prepared in DMSO and was diluted to $0.5 \mathrm{mM}$ into dialysis buffer supplemented with 0.5\% DMSO. DMSO was added to the protein sample to a final concentration of $1 \%$ just before loading into the calorimetric cell upon Epac2 titration with GBL. A typical titration experiment included 4 to $10 \mu \mathrm{L}$ of ligand per injection spaced with $240 \mathrm{~s}$ interval (28-30 injections total). Reference titrations were carried out by injecting ligand into the buffer. No detectable heat effects were observed upon GLB titration into either buffer or protein solution. Upon completion of the GLB titration, cAMP was titrated into the same protein sample as a positive control to confirm that cAMP binding activity was still present.

\section{RESULTS}

To determine if sulfonylureas can directly activate Epac2, we monitored the ability of purified Epac2 to stimulate nucleotide exchange activity of Rap 1 in the presence of various concentrations of GLB and tolbutamide (TLB), two commonly used sulfonylureas for treating diabetes, using a well-established assay where Rap1-bound fluorescent Mant-GDP is exchanged against an excess free GDP. Released Mant-GDP has a decreased fluorescence compared to bound Mant-GDP. As shown in Figure 1, Epac2 alone was not capable of stimulating the Mant-GDP-dissociation. GLB at various concentra-

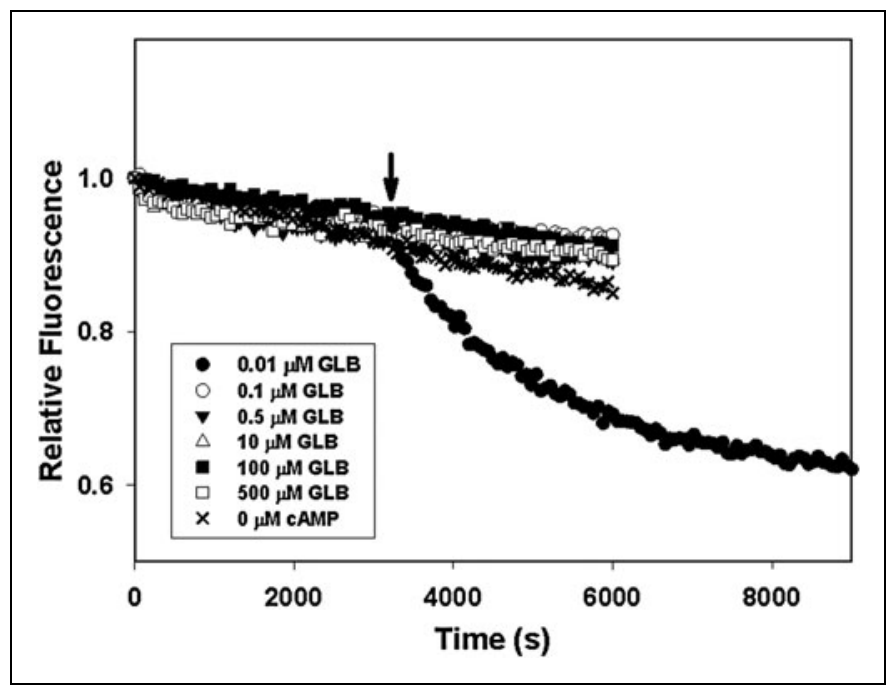

Fig. 1. Guanine nucleotide exchange factor (GEF) activity of Epac2 in the presence of various concentrations of GLB. The rates of nucleotide exchange of Mant-GDP by GDP were measured as a timedependent decrease in fluorescence intensity in the presence of various concentrations of GLB as indicated. The arrow indicates the addition of cAMP at a final concentration of $300 \mu \mathrm{M}$. Epac2, exchange protein directly activated by cyclic AMP isoform 2; GLB, glibenclamide; Mant-GDP, 3'-O-( $\mathrm{N}$-methylanthraniloyl) guanosine diphosphate.

tions from 0.001 to $100 \mu \mathrm{M}$ failed to activate Epac2, whereas addition of $300 \mu \mathrm{M}$ cAMP led to a robust activation of Mant-GDP dissociation. Similar results were obtained when TLB was tested between concentration ranges of 1 to $1,100 \mu \mathrm{M}$ (Fig. 2). It was reported by Zhang et al. in an indirect cell-based assay that the median $\mathrm{IC}_{50}$ values of GLB and TLB for Epac2 were $25 \mathrm{nM}$ and $240 \mu \mathrm{M}$, respectively. Our test concentration ranges span well beyond these $\mathrm{IC}_{50}$ values. Therefore, our observations suggest that sulfonylureas alone, such as GLB or TLB, are unable to activate Epac2.

Although GLB and TLB are incapable of directly activating Epac2, it is possible that these drugs may synergistically activate Epac2 when used in combination with cAMP. To test this possibility, we performed the Epac2 GEF assay in the presence of $100 \mu \mathrm{M}$ of cAMP, $100 \mathrm{nM}$ GLB and $100 \mu \mathrm{M}$ of cAMP, or $100 \mu \mathrm{M}$ of TLB and $100 \mu \mathrm{M}$ of cAMP. Essentially identical kinetic profiles of Mant-GDP dissociation were observed for Epac2 in the presence of cAMP with or without GLB or TLB (Fig. 3). In addition, when the initial rates of Mant-GDP release were calculated, apparent $\mathrm{k}_{\mathrm{off}}$ values around $0.6 \times 10^{-3} \mathrm{~s}^{-1}$ was obtained. Taken together, our studies provide strong evidence that GLB and TLB do not activate Epac2 when used alone or in combination with cAMP.

To test if sulfonylureas can interact with Epac2 and compete with cAMP binding, we developed a competition binding assay employing a fluorescent cAMP analog, 8-NBD-cAMP. Although 8-NBD-cAMP is almost fluorescence-less in aqueous solution, binding of 8-NBD-cAMP to Epac2 leads to a dose-dependent and large increase in fluorescent signal. ${ }^{12}$ As expected, the fluorescence increases seen with Epac2:8-NBD-cAMP can be reversed dose 


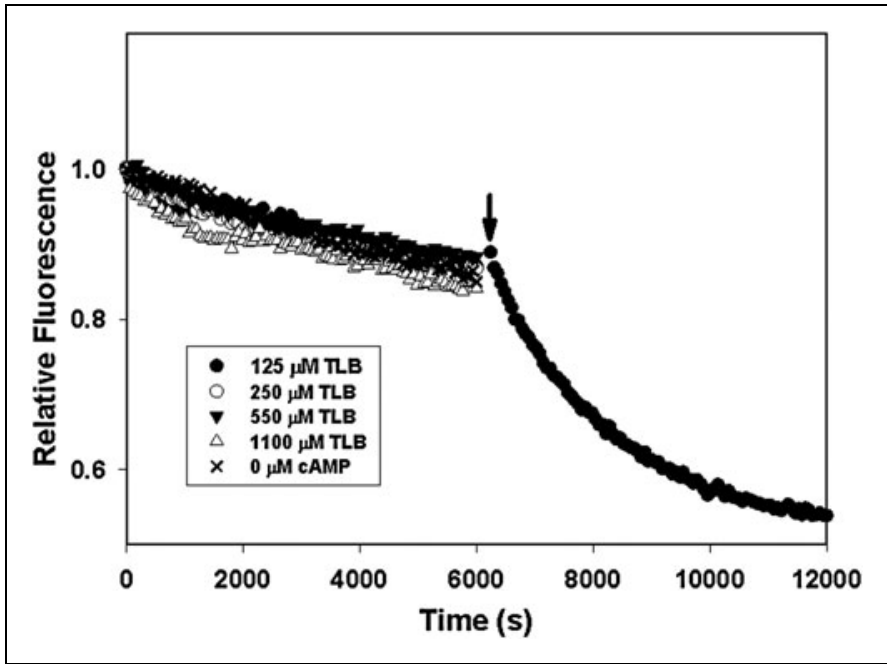

Fig. 2. GEF activity of Epac2 in the presence of various concentrations of TLB. The rates of nucleotide exchange of Mant-GDP by GDP were measured as a time-dependent decrease in fluorescence intensity in the presence of various concentrations of TLB as indicated. The arrow indicates the addition of CAMP at a final concentration of $300 \mu \mathrm{M}$. TLB, Tolbutamide [1-butyl-3-(4-methylphenylsulfonyl)urea].

dependently by the addition of unlabeled cAMP, which competes with 8-NBD-cAMP in binding to Epac2. On the other hand, GLB did not compete with 8-NBD-cAMP binding over a concentration range from $0.75 \mathrm{nM}$ to $500 \mu \mathrm{M}$ (Fig. 4). Failure of GLB to compete with 8-NBD-cAMP binding does not exclude that GLB may bind to Epac2 at a site that is distinct from the cAMP-binding site. In fact, Zhang et al. reported that 8-Br-cAMP failed to block binding of radi-

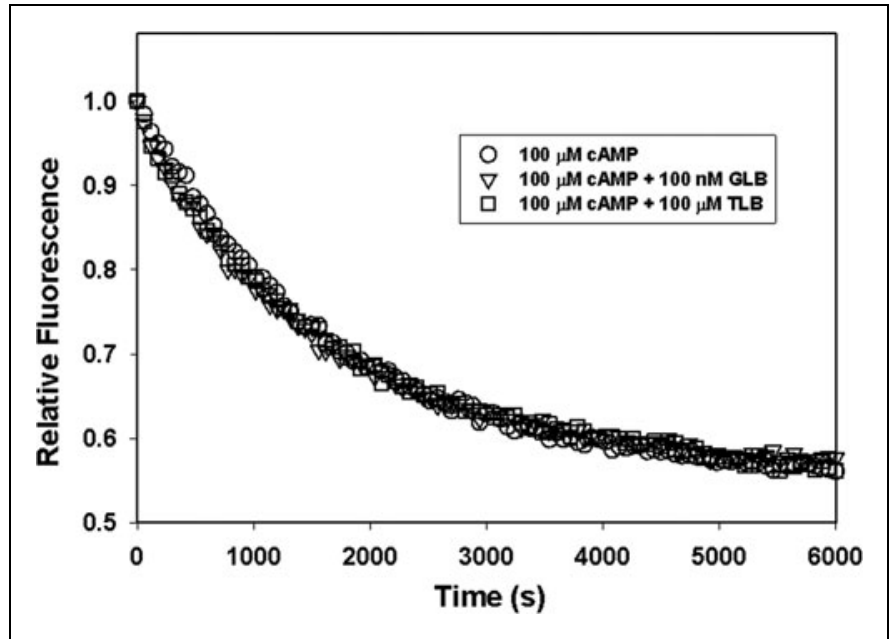

Fig. 3. GEF activity of Epac2 in the presence of cAMP and sulfonylureas. The rates of nucleotide exchange of Mant-GDP by GDP were measured as a time-dependent decrease in fluorescence intensity in the presence of $100 \mu \mathrm{M}$ cAMP alone or plus $100 \mathrm{nM} \mathrm{GLB}$ or $100 \mu \mathrm{M}$ TBL as indicated.

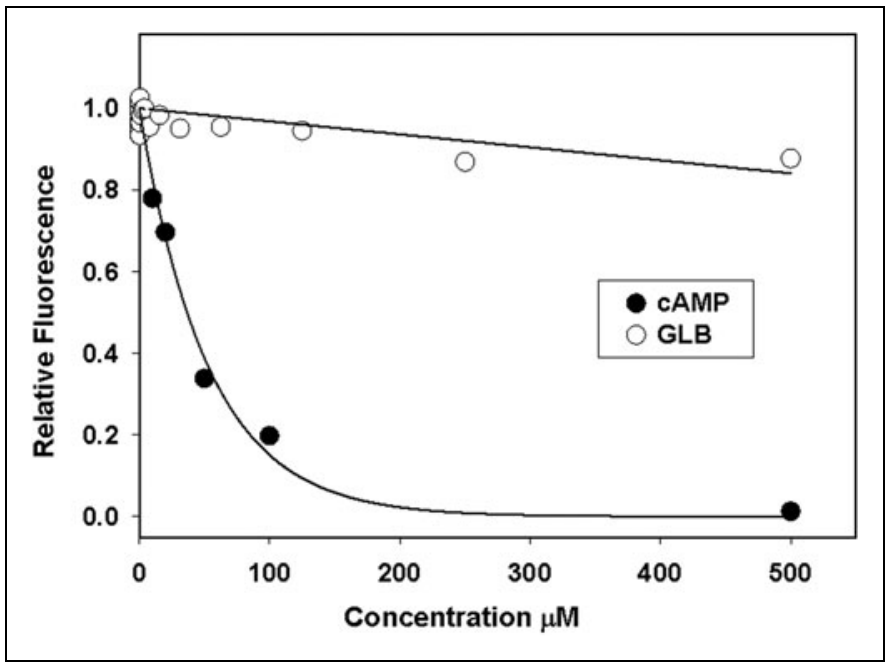

Fig. 4. Dose-dependent competition of 8-NBD-cAMP binding to Epac2. Change in fluorescence intensity of 8-NBD-cAMP in the presence of Epac2 as a function of CAMP or GLB concentrations. 8-NBD-cAMP, 8-[[2-[(7-nitro-4-benzofurazanyl)amino]ethyl] thio]adenosine- $3^{\prime}, 5^{\prime}$-cyclic monophosphate.

olabeled $\left[\mathrm{H}^{3}\right] \mathrm{GLB}$ to COS-1 cells with ectopically expressed fulllength Epac2. They interpret this observation to suggest that there is another site outside the CAMP-binding site for the action of sulfonylureas. ${ }^{1}$ To determine if GLB is capable of binding to Epac2 regardless whether GLB competes with cAMP or not, we monitored potential binding between GLB and Epac2 using ITC that directly measures the heat released or absorbed during a biomolecular binding event. As shown in Figure 5A, when GLB was titrated into purified Epac2 protein solution, no apparent heat exchange was observed in a GLB concentration range span from 3.5 to $90 \mu \mathrm{M}$. On the other hand, when cAMP solution was injected at the end of GLB titration, robust heat changes were observed (Fig. 5A). The binding isotherm for cAMP derived from the integrated heat data can be fitted by a model of two sequential binding sites with apparent binding constants of $2.4 \pm 0.5 \times 10^{4}$ and $1.4 \pm 0.7 \times 10^{4} \mathrm{M}^{-1}$, respectively. These results suggest that GLB does not bind to Epac2 or that binding of GLB to Epac2 does not involve heat changes. To distinguish between these two possibilities, we performed equilibrium dialysis using radiolabeled $\left[\mathrm{H}^{3}\right] \mathrm{GLB}$. Again, no binding was observed for $\left[\mathrm{H}^{3}\right] \mathrm{GLB}$ at all concentrations tested. Taken together, we conclude that GLB is not capable of binding to Epac2 and that Epac2 is not a direct target of sulfonylureas.

\section{CONCLUSION}

In this study, a series of well-controlled in vitro studies fail to detect direct binding of sulfonylureas to Epac2, nor are sulfonylurea drugs capable of stimulating Epac2-mediated Rap1 activation when purified full-length Epac2 and Rap1 protein are used. Therefore, the effects of antidiabetic sulfonylurea drugs on Epac2 as reported by Zhang et al. are most likely indirect. One possibility is that sulfonylurea drugs may activate Epac 2 by increasing the intracellular 

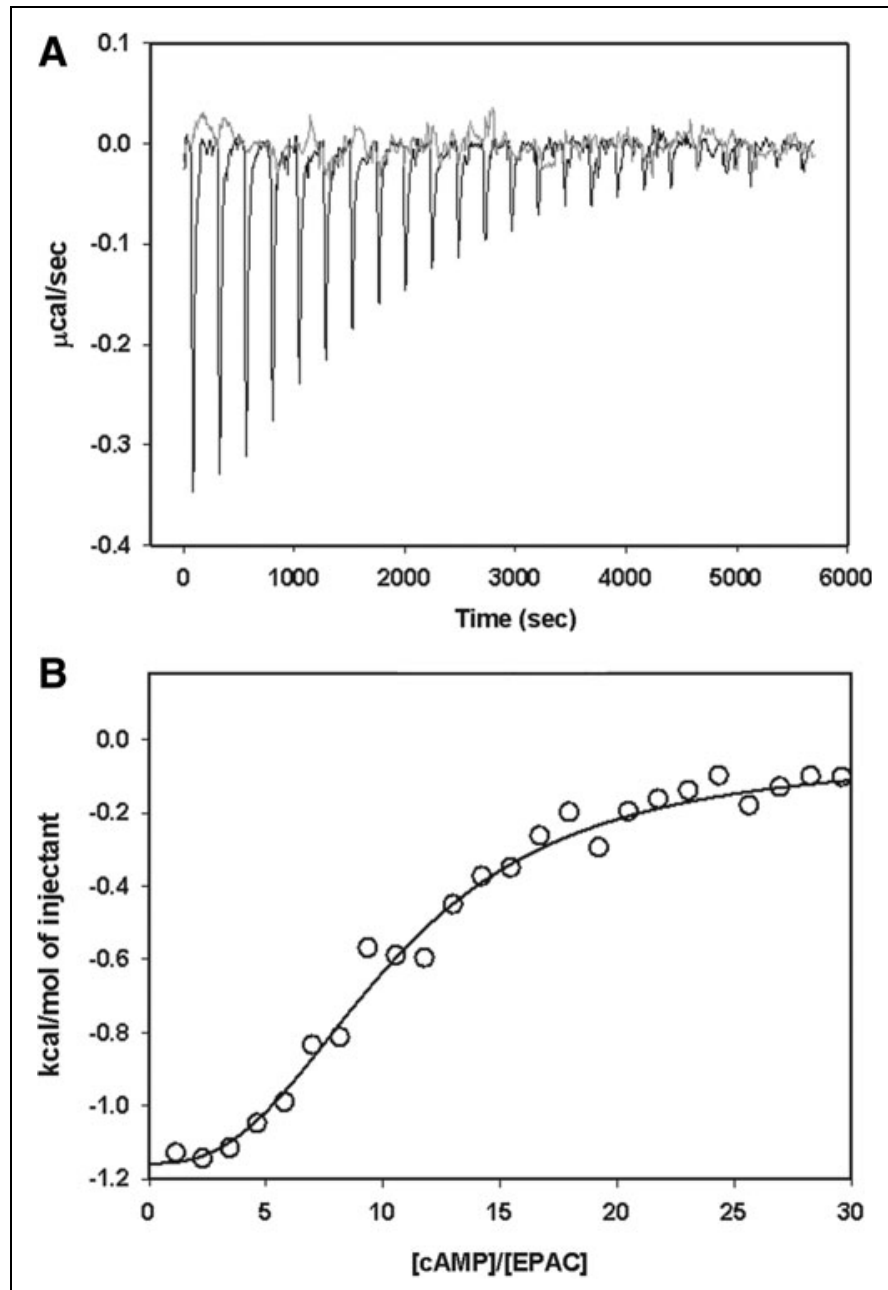

Fig. 5. Binding of GLB and CAMP to Epac2 as monitored by Isothermal titration calorimetry. (A) Raw Isothermal titration calorimetry data of Epac2 titrated with GLB (gray) and CAMP (black). (B) Binding isotherm expressed as the integrated heat data corrected for dilution.

cAMP concentration as earlier studies have shown that TLB and GLB can rapidly raise levels of cAMP in islets. ${ }^{14,15}$ However, Zhang et al. showed that treatment of MIN6 and COS-1 cells, as well as isolated mice pancreatic islets with $500 \mu \mathrm{M}$ TBL for $2 \mathrm{~min}$, failed to increase intracellular cAMP level in their Science report. ${ }^{1}$ Clearly, additional well-controlled studies are required to reveal the real mechanism of sulfonylurea induced Epac2 activation.

\section{DISCLOSURE STATEMENT}

The authors have nothing to disclose.

\section{REFERENCES}

1. Zhang $C L$, Katoh $M$, Shibasaki $T$, Minami $K$, Sunaga $Y$, Takahashi $H$, Yokoi $N$, Iwasaki M, Miki T, Seino S: The cAMP sensor Epac2 is a direct target of antidiabetic sulfonylurea drugs. Science 2009;325:607-610.

2. de Rooij J, Zwartkruis FJ, Verheijen MH, Cool RH, Nijman SM, Wittinghofer A, Bos JL: Epac is a Rap1 guanine-nucleotide-exchange factor directly activated by cyclic AMP. Nature 1998;396:474-477.

3. Kawasaki H, Springett GM, Mochizuki N, Toki S, Nakaya M, Matsuda M, Housman DE, Graybiel AM: A family of CAMP-binding proteins that directly activate Rap1. Science 1998;282:2275-2279.

4. Cheng X, Ji Z, Tsalkova T, Mei F: Epac and PKA: a tale of two intracellular cAMP receptors. Acta Biochim Biophys Sin (Shanghai) 2008;40:651-662.

5. Gloerich M, Bos JL: Epac: defining a new mechanism for CAMP action. Annu Rev Pharmacol Toxicol 2010;50:355-375.

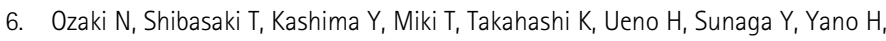
Matsuura $Y$, Iwanaga T, Takai $Y$, Seino S: cAMP-GEFll is a direct target of cAMP in regulated exocytosis. Nat Cell Biol 2000;2:805-811.

7. Leech CA, Holz GG, Chepurny O, Habener JF: Expression of cAMP-regulated guanine nucleotide exchange factors in pancreatic beta-cells. Biochem Biophys Res Commun 2000;278:44-47.

8. Holz GG: Epac: a new cAMP-binding protein in support of glucagon-like peptide-1 receptor-mediated signal transduction in the pancreatic beta-cell. Diabetes 2004;53:5-13.

9. Kang G, Joseph JW, Chepurny OG, Monaco M, Wheeler MB, Bos JL, Schwede F, Genieser HG, Holz GG: Epac-selective cAMP analog 8-pCPT-2'-0-Me-cAMP as a stimulus for $\mathrm{Ca} 2+-$-induced $\mathrm{Ca} 2+$ release and exocytosis in pancreatic betacells. J Biol Chem 2003;278:8279-8285.

10. Kang G, Chepurny OG, Malester B, Rindler MJ, Rehmann H, Bos JL, Schwede F, Coetzee WA, Holz GG: cAMP sensor Epac as a determinant of ATP-sensitive potassium channel activity in human pancreatic beta cells and rat INS-1 cells. J Physiol 2006;573 (Pt 3):595-609.

11. van den $B N$, Cool $R H$, Horn $G$, Wittinghofer A: Biochemical characterization of C3G: an exchange factor that discriminates between Rap1 and Rap2 and is not inhibited by Rap1A(S17N). Oncogene 1997;15:845-850.

12. Tsalkova $T$, Blumenthal DK, Mei FC, White MA, Cheng $X$ : Mechanism of Epac activation: structural and functional analyses of Epac2 hinge mutants with constitutive and reduced activities. J Biol Chem 2009;284: 23644-23651.

13. Kraemer A, Rehmann HR, Cool RH, Theiss C, de Rooij J, Bos JL, Wittinghofer A: Dynamic interaction of cAMP with the Rap guanine-nucleotide exchange factor Epac1. J Mol Biol 2001;306:1167-1177.

14. Charles MA, Lawecki J, Steiner AL, Grodsky GM: Cyclic nucleotides in pancreatic islets. Tolbutamide- and arginine-induced insulin release. Diabetes 1976; 25:256-259.

15. Grill V: Cyclic AMP and insulin release. Acta Paediatr Scand Supp/ 1977;(270): 41-47.

Address correspondence to: Xiaodong Cheng, Ph.D. Department of Pharmacology and Toxicology The University of Texas Medical Branch

301 University Blvd.

Galveston, TX 77555-0615

E-mail: xcheng@utmb.edu 